\title{
Effects of dietary energy levels on rumen bacterial community composition in Holstein heifers under the same forage to concentrate ratio condition
}

\author{
Yanliang Bi, Shuqin Zeng, Rong Zhang, Qiyu Diao* and Yan Tu*
}

\begin{abstract}
Background: The rumen bacterial community plays a critical role in feeds degradation and productivity. The effects of different forage to concentrate ratios on the ruminal microbial population structure have been studied extensively; however, research into changes in the ruminal bacterial community composition in heifers fed different energy level diets, with the same forage to concentrate ratio, has been very limited. The purpose of this study was to investigate the effects of different dietary energy levels, with the same forage to concentrate ratio, on ruminal bacterial community composition of heifers. Furthermore, we also determine the relationship between rumen bacteria and ruminal fermentation parameters.

Results: The 16S rRNA gene sequencing showed that, under the same forage to concentrate ratio of 50:50, an 8\% difference in dietary energy level had no significant impact on the alpha diversity and the relative abundance of the major phyla and most of the major genera in heifers. In all the treatments groups, Firmicutes, Bacteroidetes, and Proteobacteria were the dominant phyla. Spearman correlation analysis between the relative abundances of the rumen bacteria at the genus level and the fermentation parameters showed that the relative abundances of Prevotella and BF311 were positively correlated with the ammonia nitrogen and butyrate concentrations, and these two genera were negatively correlated with the propionate and isovalerate concentrations, respectively, and the genus Bifidobacterium was positively correlated with the butyrate concentration and was negatively correlated with propionate and isovalerate concentration. The total volatile fatty acid concentration was positively correlated with BF311 abundances, and was negatively correlated with Trichococcus and Facklamia abundances.

Conclusions: Under the same forage to concentrate ratio condition of 50:50, an 8\% difference in dietary energy levels had little impact on rumen bacterial community composition in heifers. The correlations between some genera of ruminal bacteria and the concentrations of volatile fatty acids and ammonia nitrogen might be indicative that the ruminal fermentation parameters are strongly influenced by the rumen bacterial community composition.
\end{abstract}

Keywords: Dietary energy level, Forage to concentrate ratio, Heifer, Rumen bacterial community, Sequencing

\footnotetext{
*Correspondence: diaoqiyu@caas.cn; tuyan@caas.cn

Key Laboratory of Feed Biotechnology of the Ministry of Agriculture, Feed

Research Institute, Chinese Academy of Agricultural Sciences, NO. 12

Zhongguancun South Street, Haidian District, Beijing 100081, China
}

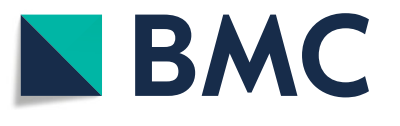

(c) The Author(s). 2018 Open Access This article is distributed under the terms of the Creative Commons Attribution 4.0 International License (http://creativecommons.org/licenses/by/4.0/), which permits unrestricted use, distribution, and reproduction in any medium, provided you give appropriate credit to the original author(s) and the source, provide a link to the Creative Commons license, and indicate if changes were made. The Creative Commons Public Domain Dedication waiver (http://creativecommons.org/publicdomain/zero/1.0/) applies to the data made available in this article, unless otherwise stated. 


\section{Background}

The rumen is an extremely complex microbial ecosystem, and contains a great diversity of bacteria, archaea, viruses, protozoa, and fungi [1]. The ruminal microorganisms play an important role in degrading complex feeds into volatile fatty acids (VFA) and ammonia, and synthesizing vitamin B and microbial cell protein, which are critical for animal health and production performance [2-4].

The structure of the ruminal microbial community is influenced by several factors, such as age, diet, health status, host species, geographical location, and whether the host has received antibiotic treatment $[5,6]$. Diet is a major factor that determines rumen community structure and microbial fermentation patterns [7-9]. For example, during adaptation to a high-grain diet from a high-forage diet, significant changes in the rumen bacterial population structure and major fermentation products have been reported [10-12]. A forage-based diet is dominated by cellulolytic and fibrolytic bacteria, which degrade the cellulose and hemicellulose, while a concentrate-based diet is dominated by starch-degrading amylolytic bacteria, which ferment the starch and sugars. Diet has a clear effect in shaping the ruminal microbial community; meanwhile, the structure of the ruminal bacterial community has been proven to have a correlation with feed efficiency [8, 13]. A previous study showed that changes in the ruminal microbial population structure could help promote feed efficiency and mean daily gain in cattle [14].

In the feedlot cattle industry, it is common to improve mean daily gain and production performance by increasing the dietary energy density. Two prevalent methods widely used to increase the dietary energy density are changing the forage to concentrate ratio and changing the dietary energy levels under the same forage to concentrate ratio condition. A change in the forage to concentrate ratio is direct and allows for increasing the dietary energy density to a great extent. However, when a forage diet is abruptly changed to a high-grain diet, a rapid decrease in ruminal $\mathrm{pH}$ due to lactic acid production has been reported $[15,16]$, which may lead to digestive disorders such as ruminal acidosis [14, 17, 18]. Ruminal acidosis is an important example of an interaction between ruminal microorganism and diet that can impair animal health and production $[19,20]$. The change in dietary energy levels under the same forage to concentrate ratio condition is a limited increase in the diet energy density, thus giving few opportunities to cause ruminal acidosis.

Understanding the dynamic ruminal microbial community and its functions is essential to facilitate feed management practices that improve optimal production efficiency [9, 11]. Many studies have examined the effects of different forage to concentrate ratios on the rumen microbial population structure [7, 10-12]. However, there is little published information on the effects of different dietary energy levels with the same forage to concentrate ratio on the ruminal bacterial community composition in cattle. Therefore, the aim of this study was to investigate the sequential dynamic changes in bacterial community composition of heifers fed different energy level diets with the same forage to concentrate ratio using next-generation sequencing technologies, and to explore their relationships with ruminal fermentation parameters. The hypothesis was that under the same forage to concentrate ratio condition, different dietary energy levels would significantly affect the rumen bacterial community composition of Holstein heifers.

\section{Methods}

Animal experiments and sample collection

The experimental procedures used in this study were approved by the Animal Ethics Committee of the Chinese Academy of Agricultural Sciences and were performed in accordance with good scientific practices and national legislation.

Twelve Chinese Holstein heifers (7 months old; body weight $268.10 \pm 7.32 \mathrm{~kg}$ ) fed the same diet were selected from a commercial dairy farm and randomly divided into three dietary treatments with four heifers each. The heifers were fed total mixed rations (Table 1) with 9.34 (low, L), 10.08 (medium, M), and 10.88 (high, H) MJ/kg dry matter of metabolizable energy for 90 days in a same season. The three kinds of diets had the same forage to concentrate ratio of 50:50. The dietary energy level of the $M$ group was formulated according to the Nutrient Requirements of Dairy Cattle [21] recommendations, and the dietary energy levels of the $\mathrm{L}$ and $\mathrm{H}$ groups were 92 and $108 \%$ of the M group, respectively. In this study, with the same ingredients and the same forage to concentrate ratio, but without fat supplementation, $8 \%$ difference of dietary energy level was the upper limit we could formulate between the two adjacent diets, so we choose these three different energy levels. The amount of feed for the three treatments was the same and was calculated to be $2.6 \%$ of the mean weight of the $M$ group. The feed intake of each heifer was recorded daily. Clean fresh water was provided ad libitum throughout the study.

At 240, 270, and 300 days of age, $2 \mathrm{~h}$ after the morning feeding, a rumen sample (both solid and liquid fractions) was extracted using esophageal tubing as described by Paz et al. [22]. Immediately after collection, $2 \mathrm{ml}$ of the rumen sample was taken and stored in liquid nitrogen until needed for DNA extraction, and the rest of the rumen sample was filtered through four layers of sterile cheesecloth. A filtered liquid sample of $10 \mathrm{ml}$ was collected, acidified with $2 \mathrm{ml} 25 \%(w / v)$ metaphosphoric 
Table 1 Composition and nutrient levels of the experimental diets (on a dry matter basis)

\begin{tabular}{|c|c|c|c|}
\hline \multirow{2}{*}{ Items } & \multicolumn{3}{|c|}{ Treatments } \\
\hline & $\mathrm{L}$ & M & $\mathrm{H}$ \\
\hline \multicolumn{4}{|l|}{ Ingredient } \\
\hline Chinese wildrye & 12.50 & 12.50 & 12.50 \\
\hline Dry alfalfa hay & 16.50 & 16.50 & 16.50 \\
\hline Corn silage & 21.00 & 21.00 & 21.00 \\
\hline Corn & 12.90 & 18.12 & 27.85 \\
\hline Wheat bran & 12 & 10 & 8.29 \\
\hline Soybean meal & 5 & 4.44 & 4 \\
\hline DDGS $^{a}$ & 5 & 5 & 4.86 \\
\hline Cottonseed meal & 4.02 & 3 & 3 \\
\hline Rice hull powder & 9.08 & 7.44 & 0 \\
\hline Premix ${ }^{b}$ & 2.00 & 2.00 & 2.00 \\
\hline Total & 100.00 & 100.00 & 100.00 \\
\hline \multicolumn{4}{|l|}{ Nutrient level } \\
\hline Dry matter (\%) & 89.43 & 89.45 & 89.64 \\
\hline Metabolizable energy ${ }^{\mathrm{C}}(\mathrm{MJ} / \mathrm{kg})$ & 9.34 & 10.08 & 10.88 \\
\hline$C P^{d}(\%)$ & 14.09 & 14.06 & 14.12 \\
\hline $\operatorname{NDF}^{d}(\%)$ & 50.52 & 48.27 & 42.74 \\
\hline $\operatorname{ADF}^{\mathrm{d}}(\%)$ & 35.13 & 33.41 & 29.19 \\
\hline Ash (\%) & 7.61 & 6.93 & 5.69 \\
\hline Calcium (\%) & 0.97 & 0.94 & 0.92 \\
\hline Phosphorous (\%) & 0.46 & 0.46 & 0.46 \\
\hline
\end{tabular}

${ }^{a}$ DDGS, distillers dried grains with soluble

${ }^{b}$ Manufactured by the Precision Animal Nutrition Research Centre, Beijing, China. Premix provided the following per $\mathrm{kg}$ of concentrate: vitamin $\mathrm{A}$,

$30150 \mathrm{IU}$; vitamin D, $9675 \mathrm{IU}$; vitamin E, $76.5 \mathrm{mg} ; \mathrm{Fe}, 132 \mathrm{mg} ; \mathrm{Cu}, 26 \mathrm{mg} ; \mathrm{Mn}$,

$118.30 \mathrm{mg}$ Z Zn, 166 mg; Se, 0.07 mg; l, $0.11 \mathrm{mg} ; \mathrm{Co}, 0.03 \mathrm{mg}$; Ca, $6.76 \mathrm{~g}$;

$\mathrm{P}, 0.68 \mathrm{~g}$

'Metabolizable energy was calculated according to the Nutrient Requirements of Dairy Cattle (NRC, 2001)

${ }^{\mathrm{d}} C P$, Crude protein; $N D F$, Neutral detergent fiber; $A D F$, Acid detergent fiber

acid, and stored at $-20{ }^{\circ} \mathrm{C}$ for analysis of ruminal fermentation parameters.

\section{Deoxyribonucleic acid (DNA) extraction, amplification, and sequencing}

Bacterial DNA was extracted from the rumen samples using an E.Z.N.A. ${ }^{\circ}$ Stool DNA kit (Omega Bio-tek, Norcross, GA, USA). The quality and quantity of the DNA were measured using an ND 1000 spectrophotometer (NanoDrop Technologies Inc., Wilmington, DE, USA). Conventional polymerase chain reaction (PCR) was performed to amplify the V3-V4 regions of the $16 \mathrm{~S}$ ribosomal ribonucleic acid (rRNA) gene using universal primers 338F 5'-barcode-ACTCCTACGGGAGGCAG CAG-3' and 806R 5' - barcode-GGACTACHVGGGTW TCTAAT-3' [23], where the barcode is an eight-base sequence unique to each sample. PCR was performed in triplicate $50 \mu \mathrm{l}$ reactions containing $30 \mathrm{ng}$ DNA template,
$2 \mu \mathrm{l}$ of each primer $(10 \mu \mathrm{M}), 4 \mu \mathrm{l} 2.5 \mathrm{mM}$ deoxyribonucleotides triphosphate (dNTPs), $5 \mu \mathrm{l} 10 \times$ Pyrobest Buffer, $0.3 \mu \mathrm{l}$ Pyrobest DNA Polymerase $(2.5 \mathrm{U} / \mu \mathrm{l}$; TaKaRa Bio Inc., Kusatsu, Shiga, Japan; code DR005A), and $36.7 \mu \mathrm{l}$ double distilled $\mathrm{H}_{2} \mathrm{O}\left(\mathrm{ddH}_{2} \mathrm{O}\right)$. Reaction conditions consisted of: an initial cycle of $95{ }^{\circ} \mathrm{C}$ for $5 \mathrm{~min}$; followed by 25 cycles of $95{ }^{\circ} \mathrm{C}$ for $30 \mathrm{~s}, 56^{\circ} \mathrm{C}$ for $30 \mathrm{~s}$, and $72{ }^{\circ} \mathrm{C}$ for $40 \mathrm{~s}$; and a final extension of $72{ }^{\circ} \mathrm{C}$ for $10 \mathrm{~min}$. PCR products were excised from $2 \%$ agarose gels, purified using an AxyPrep DNA Gel Extraction kit (Axygen Biosciences, Union City, CA, USA) and quantified using the QuantiFluor $^{\text {Tro }}$-ST system (Promega, Madison, WI, USA). Equimolar amounts of the barcoded V3-V4 amplicons were pooled and paired-end sequenced on an Illumina MiSeq PE300 platform (Illumina, Inc., San Diego, CA, USA).

\section{Sequencing data processing and analysis}

Raw data of sequencing were filtered through a quality control pipeline using Trimmomatic [24]. In brief, the 300 base pair (bp) reads were truncated at any site receiving a mean quality score of $<20$ over a $50 \mathrm{bp}$ sliding window, and any read containing barcode/primer errors or ambiguous character was discarded. Only sequences that overlapped $>10$ bp and had $<10 \%$ mismatches were assembled. Barcodes and adaptor sequences were then removed from the assembled sequences. Chimeric sequences were detected using USEARCH and removed [25]. The assembled sequences were trimmed of primers and were assigned to operational taxonomic units (OTUs) at a 97\% identity threshold using UPARSE [26]. Taxonomy classifications were assigned against the SILVA bacteria alignment database [27] using the Ribosomal Database Project (RDP) classifier [28] with a 0.8 confidence threshold. Sequences were aligned by Python Nearest Alignment Space Termination (PyNAST) [29], and a phylogenetic tree was constructed using FastTree [30].

Alpha diversity values for rumen bacterial communities of different treatments were calculated by various diversity indices (the number of OTUs, the ACE and Chaol estimator, and the Shannon index) and by normalizing the number of reads in all samples to 13,010 sequences using mothur [31].

\section{Ruminal fermentation parameters analysis}

Ruminal VFA were measured using a gas chromatograph (GC522: Wufeng Instruments, Shanghai, China) that was equipped with a hydrogen flame ionization detector and a $15 \mathrm{ml}$ semi-capillary glass column $(0.53 \mathrm{~mm}$ in diameter). Ruminal ammonia nitrogen $\left(\mathrm{NH}_{3}-\mathrm{N}\right)$ was measured as described previously [32]. 


\section{Statistical analyses}

The relative abundances of communities at the phylum and genus levels, the alpha diversity indices, and the ruminal fermentation parameters were assessed by analysis of variance using the MIXED procedure of SAS (version 9.2; SAS Institute Inc., Cary, NC, USA). The model included the fixed effects of treatment and age, interaction between treatment and age, and the random effect of the individual nested within treatment. Statistical differences among the means of the treatments were compared using Duncan's Multiple Range Test. Treatment differences with $P<0.05$ were considered statistically significant, and $0.05 \leq P<0.10$ was designated as a tendency.

Spearman's rank correlations between the relative abundances of rumen bacterial community components and fermentation parameters were analyzed using the PROC CORR procedure of SAS. Only genera with a relative abundance $\geq 0.1 \%$ in all samples were included in the analysis. $P$ $<0.05$ was considered to be a significant correlation.

\section{Results}

Sequencing depth, coverage, and alpha diversity

After data filtering, quality control, and chimera removal, a total of 3,466,038 V3-V4 16S rRNA sequence reads from the 36 samples were generated, with a mean of 96,279 sequence reads for each sample (minimum, 13,013; maximum, 276,932). The mean length of the sequence reads was $435 \mathrm{bp}$. The overall number of OTUs detected by the analysis was 16,927 based on $\geq 97 \% \mathrm{nu}-$ cleotide sequence identity between reads. With a subsample of 13,010 reads for every sample, the sample-based rarefaction curves showed that our sequencing depth provided sufficient diversity coverage to accurately describe the bacterial composition of all groups. Alpha diversity measures were indicative that, under the same forage to concentrate ratio condition, an $8 \%$ difference in dietary energy level had little effect on the number of OTUs, the ACE and Chaol estimator, and the Shannon index (Figure 1).
OTUs

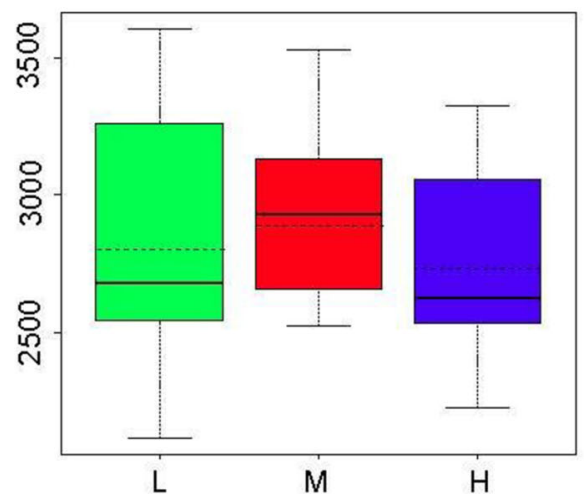

ACE

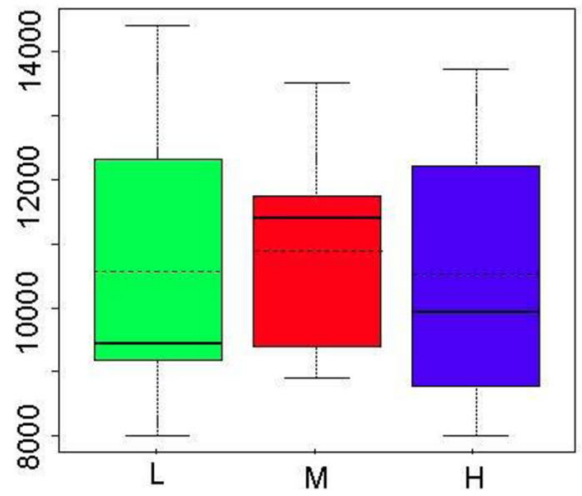

Chao1

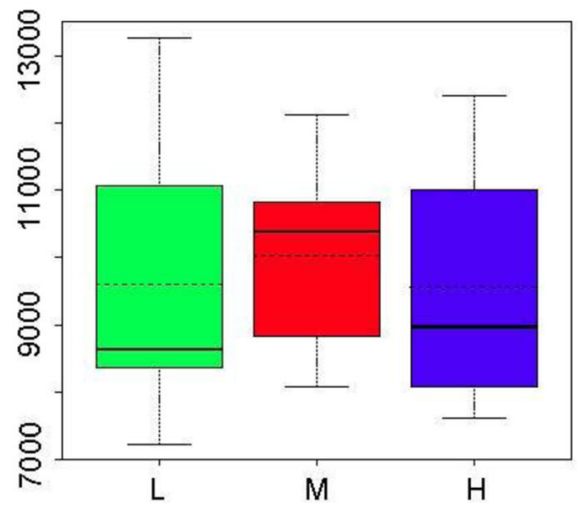

Shannon

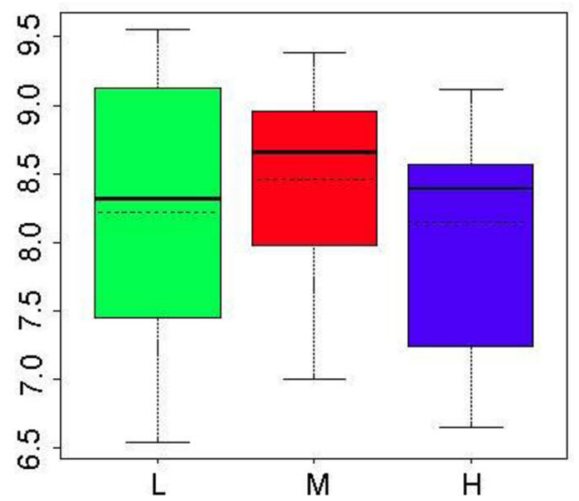

Fig. 1 Box plot showing the alpha diversity of the rumen bacterial communities in heifers given different dietary energy levels. Boxes represent the interquartile range between the first and third quartiles and the horizontal full lines inside the boxes define the median. The broken lines inside the boxes represent the mean value. Whiskers represent the maximum and minimum values within 1.5 times the interquartile range from the first and third quartiles, respectively 
Rumen bacterial community composition across different dietary treatments

At the phylum level, 42 phyla were identified in the rumen samples. Among these 42 phyla, Firmicutes, Bacteroidetes, and Proteobacteria were detected as the dominant phyla regardless of group (Table 2). In addition to these three phyla, the phyla TM7, Tenericutes, Actinobacteria, Chloroflexi, and Spirochaetes had a relative abundance of $\geq 0.1 \%$ in all groups. However, the relative abundance and composition of these predominant phyla varied among the groups. At the genus level, 346 classifiable genera were detected in all samples. In total, 26 of these genera showed a relative abundance of $\geq 0.1 \%$ in all samples across the different groups, but their relative levels of abundance were different (Table 3).

As shown in Tables 2 and 3, under the same forage to concentrate ratio condition, different dietary energy levels had little impact on the relative abundance of the major phyla and most of the major genera $(P>0.05)$, except for the genera SHD-231, Succiniclasticum, Desulfovibrio, and Psychrobacter $(P<0.05)$. The relative abundance of the genus SHD-231 significantly decreased with the increase in dietary energy levels, and this genus was significantly more abundant $(P<0.05)$ in the $\mathrm{L}$ treatment than in the $\mathrm{M}$ and $\mathrm{H}$ treatments. The relative abundances of the genera Succiniclasticum and Psychrobacter significantly increased with the increase in dietary energy levels. The relative abundance of the genus Succiniclasticum was significantly higher $(P<0.05)$ in the $\mathrm{H}$ treatment than in the $\mathrm{L}$ treatment, and the relative abundance of the genus $P s y$ chrobacter was significantly higher $(P<0.05)$ in the $\mathrm{H}$ treatment than in the $\mathrm{L}$ and $\mathrm{M}$ treatments. The genus Desulfovibrio was significantly more abundant $(P<0.05)$ in the $\mathrm{M}$ treatment than in the $\mathrm{H}$ treatment.

\section{Relationship between the rumen bacteria and fermentation parameters}

Ruminal fermentation parameters included the concentration of $\mathrm{NH}_{3}-\mathrm{N}$ and total VFA, and the molar proportions of acetate, propionate, butyrate, isovalerate, and valerate. These parameters above were not influenced by the dietary treatments (Table 4). The concentration of $\mathrm{NH}_{3}-\mathrm{N}$ and total VFA were significantly influenced by the age of the heifers, and interactions between dietary treatments and age were observed for the concentration of $\mathrm{NH}_{3}-\mathrm{N}$ and total VFA.

Correlation analysis was performed to identify the correlation between the relative abundances of the rumen bacteria and the fermentation parameters. The abundance of the rumen bacteria at the genus level and the concentrations of $\mathrm{NH}_{3}-\mathrm{N}$ and total VFA were regarded as significantly correlated with each other if $P<0.05$. The $\mathrm{NH}_{3}-\mathrm{N}$ concentration was positively correlated with the relative abundances of the genera Prevotella and BF311 (Figure 2). The propionate molar proportion was negatively correlated with the relative abundances of the genera Prevotella and Bifidobacterium, and the isovalerate molar proportion was negatively correlated with the relative abundances of the genera BF311 and Bifidobacterium. The butyrate molar proportion was positively correlated with the relative abundances of Prevotella, BF311, Butyrivibrio, and Bifidobacterium, and was negatively correlated with Psychrobacter abundance. The valerate molar proportion was positively correlated with the relative abundance of Carnobacterium. The total VFA concentration was positively correlated with BF311 abundances, and was negatively correlated with Trichococcus and Facklamia abundances.

\section{Discussion}

Rumen bacterial communities play a key role in the production performance and health of the host [33]. The objective of this study was to investigate the effects of different dietary energy levels, with the same forage to concentrate ratio, on the rumen bacterial community composition in Holstein heifers using barcoded pyrosequencing of hypervariable V3-V4 regions of the $16 \mathrm{~S}$ rRNA gene, and to explore the relationship between rumen bacteria and ruminal fermentation parameters.

Table 2 Phylum-level composition of the rumen samples from different groups of heifers (relative abundance $\geq 0.1 \%$ )

\begin{tabular}{|c|c|c|c|c|c|c|c|}
\hline \multirow[t]{2}{*}{ Phylum } & \multicolumn{3}{|c|}{ Treatments } & \multirow[t]{2}{*}{ SEM } & \multicolumn{3}{|l|}{$P$} \\
\hline & $\mathrm{L}$ & M & $\mathrm{H}$ & & Treatment & Age & Treatment $\times$ Age \\
\hline Actinobacteria & 1.97 & 1.63 & 1.33 & 0.0010 & 0.0690 & 0.0014 & 0.0989 \\
\hline Bacteroidetes & 20.8 & 23.44 & 18.69 & 0.0114 & 0.2825 & $<0.0001$ & 0.9667 \\
\hline Chloroflexi & 0.29 & 0.24 & 0.21 & 0.0003 & 0.1783 & 0.0004 & 0.1384 \\
\hline Firmicutes & 54.69 & 54.79 & 51.62 & 0.0065 & 0.1295 & $<0.0001$ & 0.3535 \\
\hline Proteobacteria & 13.41 & 10.76 & 15.57 & 0.0205 & 0.6438 & 0.0002 & 0.6974 \\
\hline Spirochaetes & 0.10 & 0.10 & 0.08 & 0.0001 & 0.7489 & 0.0001 & 0.3636 \\
\hline Tenericutes & 2.03 & 1.99 & 2.04 & 0.0017 & 0.9897 & $<0.0001$ & 0.1050 \\
\hline TM7 & 2.42 & 2.1 & 2.04 & 0.0016 & 0.6041 & 0.0191 & 0.3990 \\
\hline
\end{tabular}


Table 3 Genus-level composition of the rumen samples from different groups of heifers (relative abundance $\geq 0.1 \%$ )

\begin{tabular}{|c|c|c|c|c|c|c|c|c|}
\hline \multirow[t]{2}{*}{ Phylum } & \multirow[t]{2}{*}{ Genus } & \multicolumn{3}{|c|}{ Treatments } & \multirow[t]{2}{*}{ SEM } & \multicolumn{3}{|l|}{$P$} \\
\hline & & L & M & $\mathrm{H}$ & & Treatment & Age & Treatment $\times$ Age \\
\hline Actinobacteria & Bifidobacterium & 0.55 & 0.35 & 0.17 & 0.0008 & 0.1776 & 0.0202 & 0.0603 \\
\hline \multirow[t]{2}{*}{ Bacteroidetes } & CF231 & 0.65 & 0.74 & 0.64 & 0.0004 & 0.5347 & 0.0003 & 0.2984 \\
\hline & Prevotella & 4.63 & 5.96 & 4.41 & 0.0029 & 0.1140 & $<0.0001$ & 0.9769 \\
\hline Chloroflexi & SHD-231 & $0.29^{\mathrm{a}}$ & $0.23^{b}$ & $0.21^{b}$ & 0.0001 & 0.0249 & 0.0007 & 0.4629 \\
\hline \multirow[t]{18}{*}{ Firmicutes } & Anaerostipes & 0.17 & 0.21 & 0.18 & 0.0002 & 0.7527 & 0.5715 & 0.7874 \\
\hline & Anaerovibrio & 0.24 & 0.31 & 0.29 & 0.0002 & 0.4666 & 0.0845 & 0.6887 \\
\hline & Blautia & 0.17 & 0.33 & 0.29 & 0.0003 & 0.0994 & $<0.0001$ & 0.0309 \\
\hline & Butyrivibrio & 2.73 & 2.67 & 2.52 & 0.0010 & 0.6909 & $<0.0001$ & 0.0085 \\
\hline & Carnobacterium & 9.62 & 9.08 & 7.48 & 0.0193 & 0.8961 & 0.0258 & 0.9839 \\
\hline & Clostridium & 0.25 & 0.26 & 0.19 & 0.0002 & 0.2906 & 0.0230 & 0.5487 \\
\hline & Coprococcus & 0.32 & 0.23 & 0.17 & 0.0002 & 0.1160 & $<0.0001$ & 0.5423 \\
\hline & Facklamia & 0.19 & 0.12 & 0.06 & 0.0003 & 0.2606 & 0.0333 & 0.1067 \\
\hline & L7A_E11 & 0.12 & 0.13 & 0.13 & 0.0001 & 0.7989 & 0.9725 & 0.4593 \\
\hline & Mogibacterium & 0.84 & 0.78 & 0.86 & 0.0005 & 0.8112 & 0.0004 & 0.8287 \\
\hline & Oscillospira & 0.39 & 0.39 & 0.35 & 0.0002 & 0.6750 & 0.0046 & 0.5703 \\
\hline & p-75-a5 & 0.27 & 0.25 & 0.29 & 0.0002 & 0.6309 & 0.0010 & 0.5379 \\
\hline & RFN20 & 0.11 & 0.10 & 0.11 & 0.0001 & 0.9604 & $<0.0001$ & 0.7839 \\
\hline & Ruminococcus & 4.36 & 3.73 & 4.04 & 0.0023 & 0.5613 & $<0.0001$ & 0.6957 \\
\hline & Selenomonas & 0.09 & 0.13 & 0.11 & 0.0001 & 0.1286 & 0.2349 & 0.4714 \\
\hline & Shuttleworthia & 0.15 & 0.16 & 0.15 & 0.0001 & 0.8867 & $<0.0001$ & 0.4508 \\
\hline & Succiniclasticum & $3.48^{b}$ & $3.89^{\mathrm{ab}}$ & $4.49^{a}$ & 0.0009 & 0.0034 & 0.0090 & 0.6174 \\
\hline & Trichococcus & 0.20 & 0.13 & 0.12 & 0.0003 & 0.6035 & 0.0018 & 0.2963 \\
\hline \multirow[t]{4}{*}{ Proteobacteria } & Acinetobacter & 0.94 & 0.49 & 0.32 & 0.0017 & 0.3587 & 0.0032 & 0.3414 \\
\hline & Desulfovibrio & $0.17^{\mathrm{ab}}$ & $0.20^{\mathrm{a}}$ & $0.13^{b}$ & 0.0001 & 0.0468 & $<0.0001$ & 0.1780 \\
\hline & Pseudomonas & 0.22 & 0.12 & 0.13 & 0.0003 & 0.4600 & 0.2161 & 0.3478 \\
\hline & Psychrobacter & $0.27^{b}$ & $0.27^{b}$ & $0.43^{\mathrm{a}}$ & 0.0001 & $<0.0001$ & 0.0131 & $<0.0001$ \\
\hline
\end{tabular}

$\overline{a, b}$ Values in the same row with different superscript letters differ significantly $(P<0.05)$

Table 4 Effects of dietary energy levels on the ammonia nitrogen and volatile fatty acids (VFA) of rumen samples in heifers aged 7 to 10 months

\begin{tabular}{|c|c|c|c|c|c|c|c|}
\hline \multirow[t]{2}{*}{ Items } & \multicolumn{3}{|c|}{ Treatments } & \multirow[t]{2}{*}{ SEM } & \multicolumn{3}{|l|}{$P$} \\
\hline & L & M & $\mathrm{H}$ & & Treatment & Age & Treatment $\times$ Age \\
\hline $\mathrm{NH}_{3}-\mathrm{N}(\mathrm{mg} / \mathrm{dl})$ & 15.15 & 15.17 & 15.60 & 1.339 & 0.9650 & 0.0204 & 0.0440 \\
\hline Total VFA (mM) & 102.80 & 105.62 & 110.02 & 12.010 & 0.9131 & 0.0035 & 0.0304 \\
\hline Acetate (\%) & 67.61 & 67.37 & 67.89 & 0.0066 & 0.8586 & 0.1948 & 0.5483 \\
\hline Propionate (\%) & 20.12 & 19.80 & 20.03 & 0.0105 & 0.9766 & 0.4745 & 0.7426 \\
\hline Butyrate (\%) & 8.92 & 9.48 & 9.06 & 0.0033 & 0.4900 & 0.0630 & 0.9302 \\
\hline Valerate (\%) & 2.39 & 2.44 & 2.30 & 0.0012 & 0.7164 & 0.0607 & 0.2125 \\
\hline Isovalerate (\%) & 0.79 & 0.90 & 0.71 & 0.0009 & 0.4099 & 0.0588 & 0.5280 \\
\hline
\end{tabular}




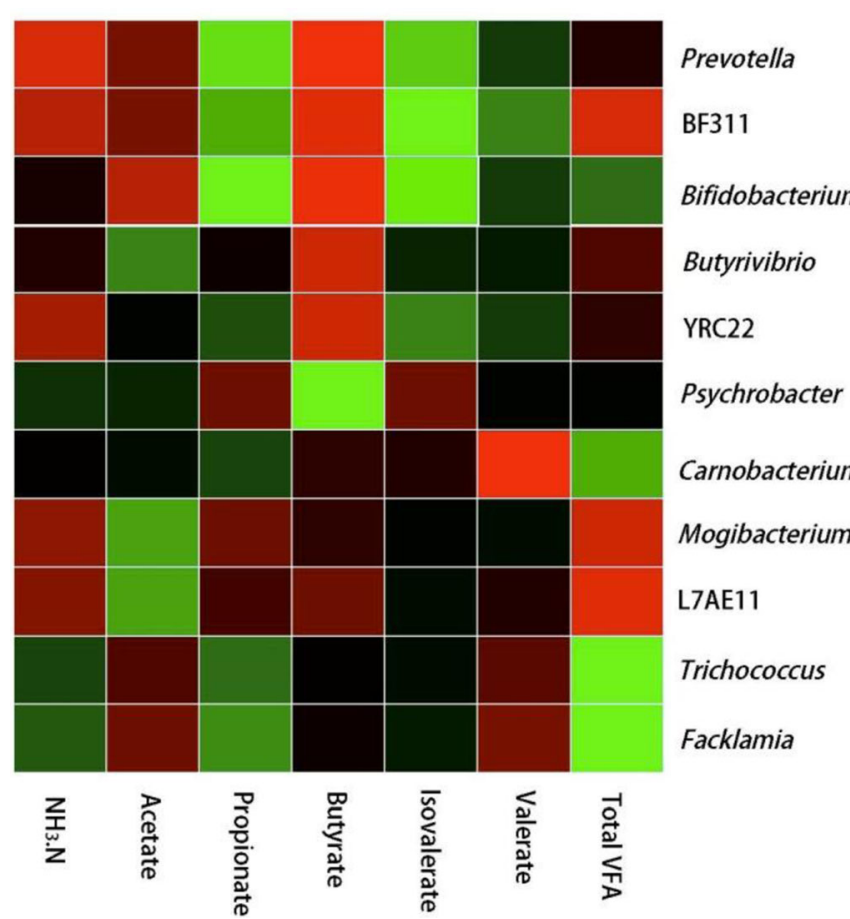

Fig. 2 Correlation between the relative abundances of the rumen bacteria and the fermentation parameters $(P<0.05$ was considered to be a significant correlation)

In this study, neither the alpha diversity nor the relative abundances of the main phyla and genera changed significantly among the different dietary treatments, indicating that, under the same forage to concentrate ratio of 50:50, dietary energy levels that varied by $8 \%$ did not affect the rumen bacterial community composition. Previous studies showed that, during transition from high-forage diets to high-grain diets, significant changes in rumen microbial population structure and diversity were detected, and a decrease in the amount of major cellulolytic bacterial species and an increase in the amount of amylolytic bacteria were observed $[7,9,10]$. Although different processing methods of ingredients affected the rumen microbial population structure $[34,35]$, under the same diet ingredients and processing conditions, the dietary forage to concentrate ratio was the main factor affecting the rumen microbial population structure. The Firmicutes, Bacteroidetes, and Proteobacteria were the dominant phyla in the rumen of heifers regardless of diet composition, and their relative abundances did not show significant changes between the groups. Similarly, at the genus level, the majority of the genera present in all groups with the relative abundance $\geq 0.1 \%$ were not affected by the different diets. The ruminal bacterial community composition in the current study was consistent with the known bacterial communities in dairy cattle, as bacteria from the phyla Firmicutes, Bacteroidetes, and Proteobacteria dominated the core bacterial community, regardless of feeding groups [20,36].
Dietary changes have important impacts on rumen bacterial communities [10, 37, 38]. Fernando et al. [11] demonstrated that, when the dietary forage to concentrate ratio gradually increased from $80: 20$ to $60: 40$ or 20:80, the rumen bacterial population structure changed clearly, with the Proteobacteria increasing, and the Firmicutes and Bacteroidetes decreasing significantly. Petri et al. [7] investigated the rumen bacterial community in heifers during the transition from forage to high-grain diets and showed that the Proteobacteria increased and Firmicutes decreased as an excess of grain was introduced into the rumen. The increased abundance of Proteobacteria during high-grain diets is suggestive of an increased need for bacterial species that can metabolize the newly available fermentable carbohydrates $[7,11]$. In this study, under the same forage to concentrate ratio of 50:50, the relative abundance of Proteobacteria increased, and Firmicutes and Bacteroidetes decreased with increasing dietary energy levels, but no significant changes were detected. Our observation of no significant changes in the abundance of most phyla may be due to the same forage to concentrate ratio in the diets, suggesting that the rumen bacterial community is mainly affected by forage to concentrate ratio, rather than the dietary energy level.

Firmicutes is the most abundant phylum accounting for more than $51 \%$ of the total sequences among different dietary treatments and is predominantly comprised 
of Ruminococcus, Butyrivibrio, Succiniclasticum, and Carnobacterium. Firmicutes are mainly composed of Gram-positive, low-G + C-content bacteria [39]. Ruminococcus is a fibrolytic organism that digests fiber and is predominantly present in high-fiber diets [1]. The abundance of Ruminococcus has been shown to gradually decrease during adaptation to a high-grain diet $[10,11]$. In this study, the abundance of Ruminococcus was not affected by the three types of diet. The finding was not surprising, as the three diets comprised the same roughage composition and proportion. Butyrivibrio is known to be a fibrolytic bacterium, but it also has the ability to utilize starch and produce butyrate [11,33], which is indicative that Butyrivibrio is able to utilize both fiber and starch to produce butyrate. This is consistent with the results of the positive correlation between the relative abundance of Butyrivibrio and the butyrate concentration. Previous studies found that the population of Butyrivibrio decreased in cattle on high-concentrate diets $[11,40]$. In this study, the relative abundance of the genus Butyrivibrio was not influenced by the increasing dietary energy levels, which is suggestive that, under the same forage to concentrate ratio, the proportion of grain increasing from 15.42 to $27.85 \%$ had little influence on the abundance of Butyrivibrio. Succiniclasticum is a propionate-producing species and is known to produce propionate through succinate decarboxylation [41, 42]. In our study, the relative abundance of Succiniclasticum significantly increased in the high-energy diet group, consistent with findings that the abundance of Succiniclasticum increases in dairy cows fed high levels of concentrate [7, 43]. The genera Carnobacterium, which are regarded as lactic acid bacteria in the rumen [44], were not affected by the different diets. This may also be because the increasing range of grain in the diets is too small to cause changes. Trichococcus can metabolize a variety of complex organic compounds, such as multiple sugars, amino acids, polyols, and fatty acids, to produce lactate [45, 46], and Trichococcus also has the ability to degrade cellulose [47]. The negative correlation between the relative abundance of Trichococcus and the total VFA concentration in this study may be because of the decrease in ruminal $\mathrm{pH}$ limiting the growth of organisms that produce VFA, due to the increased amount of lactic acid produced by lactic acid bacteria. Unfortunately, the lactic acid concentration was not detected in the current study.

Sequence analysis of the reads from animals fed the three diets displayed a larger number of bacteria belonging to the phylum Bacteroidetes and this phylum was mainly composed of bacteria belonging to the genus Prevotella. The ruminal Prevotella species are a genetically and metabolically diverse bacterial group in rumen microbial communities, and they are numerically predominant in both the rumens of animals fed high-grain diets and those fed high-forage diet $[48,49]$. Prevotella species are capable of utilizing starches, other non-cellulosic polysaccharides, and simple sugars as energy sources to produce succinate as the major fermentation end product [49]. In addition, ruminal Prevotella species, including members with hemicellulolytic and proteolytic activity [48], are considered to be involved in hemicellulose and pectin digestion [50], and protein or peptide metabolism $[51,52]$ in the rumen. In this study, the relative abundance of Prevotella was positively correlated with $\mathrm{NH}_{3}-\mathrm{N}$ and butyrate concentration. These results were consistent with previous observations reported by Chiquette et al. [53], who found that supplementation with members of the Prevotella as direct-fed microbials to dairy cows significantly increased the $\mathrm{NH}_{3}-\mathrm{N}$, acetate, and butyrate concentrations in the rumen. The increased concentration of $\mathrm{NH}_{3}-\mathrm{N}$ is suggestive of an increased rate of proteolysis and amino acid metabolism in the animals. The increased concentration of butyrate is indicative of an increased rate of fiber fermentation.

Proteobacteria was the third most dominant phylum in the rumen, which was consistent with previous observations $[20,36]$. The phylum is mainly composed of Gram-negative bacteria, which have highly diverse metabolic functions [54]. In this study, the Proteobacteria was composed of bacteria belonging to the genera Psychrobacter and Acinetobacter. The genus Psychrobacter has been regarded as containing psychrophilic organisms $[55,56]$. However, members of this genus are highly varied in their cold adaptability and genomes, and have been isolated from various environments, such as Antarctic soil and seawater, Siberian permafrost, and the gut of marine fish [57-59]. Very little is known about the metabolism of this genus. Sun et al. [60] demonstrated that supplementing the diet with Psychrobacter enhanced intestinal digestive enzyme activities and improved feed utilization. In the present study, the relative abundance of the genus Psychrobacter was significantly higher in the high energy level diet than in the other two diets, and was negatively correlated with the butyrate concentration.

Bifidobacterium belonging to the phylum Actinobacteria represent Gram-positive, non-motile, and non-spore-forming bacteria [61]. Members of Bifidobacterium have extensive capabilities to metabolize dietaryas well as host-derived glycans, in particular starch and starch-like poly- and oligo-saccharides, such as pullulan, amylopectin, maltotriose, and maltodextrin $[62,63]$. Bifidobacterium have been identified as the major lactic acid producing bacteria [64]. Lactic and acetic acids are the main metabolic end products produced by this genus [65]. The correlation analysis between the relative abundance of Bifidobacterium and the fermentation parameters showed that the former was positively correlated 
with butyrate concentration, and was negatively correlated with propionate and isovalerate concentration. The reported positive correlation between Bifidobacterium and butyrate concentration found by us in the present work is supported by previous study, in which Bifidobacterium was pointed to the involvement of butyrate production [66]. They believed that some Bifidobacterium strains were involved in butyrate production as a result of the secondary fermentation of the lactate and acetate by butyrate-producing bacteria through cross-feeding interactions [67-69]. Knowledge of substrate utilization and end products of members of the genera BF311 and Facklamia is limited, but correlation analysis showed that the metabolic capability of BF311 might be similar to the genus Prevotella, and the genus BF311 might participate in VFA metabolism. Future research of rumen bacterial community composition and functions is necessary to explain the relationship between the ruminal bacteria and the host.

\section{Conclusions}

Under the same forage to concentrate ratio condition of 50:50, an $8 \%$ difference in dietary energy levels had no significant impact on rumen bacterial community composition in heifers. Firmicutes, Bacteroidetes, and Proteobacteria were detected as the dominant phyla in all treatments groups. Furthermore, the correlations between some genera of ruminal bacteria and the concentrations of $\mathrm{NH}_{3}-\mathrm{N}$ and VFA might be indicative that the ruminal fermentation parameters are strongly influenced by the rumen bacterial community composition. This study provides further information regarding the effects of different dietary energy levels on rumen bacterial community composition in heifers, and the relationship between rumen bacteria and ruminal fermentation parameters. This study may be of great interest for researchers investigating rumen microbial ecology, rumen fermentation function, and feed management.

\section{Abbreviations}

bp: Base pair; $d \mathrm{dH}_{2} \mathrm{O}$ : Double distilled $\mathrm{H}_{2} \mathrm{O}$; DNA: Deoxyribonucleic acid; dNTPS: Deoxyribonucleotide triphosphate; $\mathrm{NH}_{3}-\mathrm{N}$ : ammonia nitrogen; OTU: Operational taxonomic units; PCR: Polymerase chain reaction; PyNAST: Python Nearest Alignment Space Termination; RDP: Ribosomal Database Project; rRNA: Ribosomal ribonucleic acid; VFA: Volatile fatty acids

\section{Acknowledgments}

The authors thank Beijing Allwegene Technology Co.,Ltd. for providing the sequcencing and analysis services in the research.

\section{Funding}

This study was supported by the Beijing Dairy Industry Innovation Consortium of Agriculture Research System and Key Laboratory of Feed Biotechnology of the Ministry of Agriculture. The funding bodies had no role in the design of the study, in data collection, analysis or interpretation, or in writing the manuscript.

\section{Availability of data and materials}

The sequencing data obtained in this study were deposited in the National Center for Biotechnology Information Sequence Read Archive under accession numbers SRR5487565 to SRR5487601.

\section{Authors' contributions}

The experiment was conceived and designed by QYD and YT, and performed by SQZ. Data analysis was performed by YLB and RZ. Paper writing were conducted by YLB. All authors read and approved the final manuscript.

\section{Authors' information}

Key Laboratory of Feed Biotechnology of the Ministry of Agriculture, Feed Research Institute, Chinese Academy of Agricultural Sciences, Beijing, BJ,

China.

Ethics approval and consent to participate

The experimental procedures used in this study were approved by the Animal Ethics Committee of the Chinese Academy of Agricultural Sciences.

Consent for publication

Not applicable.

\section{Competing interests}

The authors declare that they have no competing interests.

\section{Publisher's Note}

Springer Nature remains neutral with regard to jurisdictional claims in published maps and institutional affiliations.

Received: 26 February 2018 Accepted: 27 June 2018

Published online: 11 July 2018

\section{References}

1. Hobson P, Stewart C. The rumen microbial ecosystem. London: Blackie Academic and Professional; 1997.

2. Krause DO, Denman SE, Mackie RI, Morrison M, Rae AL, Attwood GT, McSweeney CS. Opportunities to improve fiber degradation in the rumen: microbiology, ecology, and genomics. FEMS Microbiol Rev. 2003; 27(5):663-93.

3. Zilber-Rosenberg I, Rosenberg E. Role of microorganisms in the evolution of animals and plants: the hologenome theory of evolution. FEMS Microbiol Rev. 2008;32(5):723-35.

4. Yanez-Ruiz DR, Abecia L, Newbold CJ. Manipulating rumen microbiome and fermentation through interventions during early life: a review. Front Microbiol. 2015;6:1133.

5. VIkova E, Trojanova I, Rada V. Distribution of bifidobacteria in the gastrointestinal tract of calves. Folia Microbiol. 2006;51(4):325-8.

6. Jiao J, Li X, Beauchemin KA, Tan Z, Tang S, Zhou C. Rumen development process in goats as affected by supplemental feeding v. Grazing: agerelated anatomic development, functional achievement and microbial colonisation. Brit J Nutr. 2015;113(6):888-900.

7. Petri RM, Schwaiger T, Penner GB, Beauchemin KA, Forster RJ, McKinnon JJ, McAllister TA. Characterization of the core rumen microbiome in cattle during transition from forage to concentrate as well as during and after an acidotic challenge. PLoS One. 2013;8(12):e83424.

8. Carberry CA, Kenny DA, Han S, McCabe MS, Waters SM. Effect of phenotypic residual feed intake and dietary forage content on the rumen microbial community of beef cattle. Appl Environ Microb. 2012;78(14):4949-58.

9. de Menezes AB, Lewis E, O'Donovan M, O'Neill BF, Clipson N, Doyle EM. Microbiome analysis of dairy cows fed pasture or total mixed ration diets. FEMS Microbiol Ecol. 2011;78(2):256-65.

10. Tajima K, Aminov RI, Nagamine T, Matsui H, Nakamura M, Benno Y. Dietdependent shifts in the bacterial population of the rumen revealed with real-time PCR. Appl Environ Microb. 2001;67(6):2766-74.

11. Fernando SC, Purvis HTI, Najar FZ, Sukharnikov LO, Krehbiel CR, Nagaraja TG, Roe BA, DeSilva U. Rumen microbial population dynamics during adaptation to a high-grain diet. Appl Environ Microb. 2010;76(22):7482-90.

12. Thoetkiattikul H, Mhuantong W, Laothanachareon T, Tangphatsornruang S, Pattarajinda V, Eurwilaichitr L, Champreda V. Comparative analysis of microbial profiles in cow rumen fed with different dietary fiber by tagged 165 rRNA gene pyrosequencing. Curr Microbiol. 2013;67(2):130-7. 
13. Guan LL, Nkrumah JD, Basarab JA, Moore SS. Linkage of microbial ecology to phenotype: correlation of rumen microbial ecology to cattle's feed efficiency. FEMS Microbiol Lett. 2008;288(1):85-91.

14. Bevans DW, Beauchemin KA, Schwartzkopf-Genswein KS, McKinnon JJ, McAllister TA. Effect of rapid or gradual grain adaptation on subacute acidosis and feed intake by feedlot cattle. J Anim Sci. 2005;83(5):1116-32.

15. Nocek JE. Bovine acidosis: implications on laminitis. J Dairy Sci. 1997;80(5): 1005-28.

16. Klieve AV, Hennessy D, Ouwerkerk D, Forster RJ, Mackie Rl, Attwood GT. Establishing populations of Megasphaera elsdenii YE 34 and Butyrivibrio fibrisolvens YE 44 in the rumen of cattle fed high grain diets. J Appl Microbiol. 2003;95(3):621-30.

17. Nagaraja TG, Titgemeyer EC. Ruminal acidosis in beef cattle: the current microbiological and nutritional outlook. J Dairy Sci. 2007;90S:E17-38.

18. Bramley E, Lean IJ, Fulkerson WJ, Stevenson MA, Rabiee AR, Costa ND. The definition of acidosis in dairy herds predominantly fed on pasture and concentrates. J Dairy Sci. 2008;91(1):308-21.

19. Tajima K, Arai S, Ogata K, Nagamine T, Matsui H, Nakamura M, Aminov Rl, Benno Y. Rumen bacterial community transition during adaptation to highgrain diet. Anaerobe. 2000;6(5):273-84.

20. Khafipour E, Li S, Plaizier JC, Krause DO. Rumen microbiome composition determined using two nutritional models of subacute ruminal acidosis. Appl Environ Microb. 2009;75(22):7115-24.

21. Subcommittee. On dairy cattle nutrition, committee on animal nutrition, board on agriculture and natural resources, council, National Research. In: Nutrient requirements of dairy cattle. 7th revised edition ed. Washington: National Academy Press; 2001.

22. Paz HA, Anderson CL, Muller MJ, Kononoff PJ, Fernando SC. Rumen bacterial community composition in Holstein and Jersey cows is different under same dietary condition and is not affected by sampling method. Front Microbiol. 2016;7:1-9.

23. Dennis KL, Wang Y, Blatner NR, Wang S, Saadalla A, Trudeau E, Roers A, Weaver CT, Lee JJ, Gilbert JA, et al. Adenomatous polyps are driven by microbe-instigated focal inflammation and are controlled by IL-10producing T cells. Cancer Res. 2013;73(19):5905-13.

24. Bolger AM, Lohse M, Usadel B. Trimmomatic: a flexible trimmer for Illumina sequence data. Bioinformatics. 2014;30(15):2114-20.

25. Edgar RC. Search and clustering orders of magnitude faster than BLAST. Bioinformatics. 2010;26(19):2460-1.

26. Edgar RC. UPARSE: highly accurate OTU sequences from microbial amplicon reads. Nat Methods. 2013;10(10):996

27. Quast C, Pruesse E, Yilmaz P, Gerken J, Schweer T, Yarza P, Peplies J, Gloeckner FO. The SILVA ribosomal RNA gene database project: improved data processing and web-based tools. Nucleic Acids Res. 2013;41(D1):D590-6.

28. Wang Q, Garrity GM, Tiedje JM, Cole JR. Naive Bayesian classifier for rapid assignment of rRNA sequences into the new bacterial taxonomy. Appl Environ Microb. 2007;73(16):5261-7.

29. DeSantis TZ, Hugenholtz P, Keller K, Brodie EL, Larsen N, Piceno YM, Phan R, Andersen GL. NAST: a multiple sequence alignment server for comparative analysis of 16S rRNA genes. Nucleic Acids Res. 2006;34(SI):W394-9.

30. Price MN, Dehal PS, Arkin AP. FastTree: computing large minimum evolution trees with profiles instead of a distance matrix. Mol Biol Evol. 2009;26(7): 1641-50.

31. Schloss PD, Westcott SL, Ryabin T, Hall JR, Hartmann M, Hollister EB, Lesniewski RA, Oakley BB, Parks DH, Robinson CJ, et al. Introducing mothur: open-source, platform-independent, community-supported software for describing and comparing microbial communities. Appl Environ Microb. 2009;75(23):7537-41.

32. Chaney AL, Marbach EP. Modified reagents for determination of urea and ammonia. Clin Chem. 1962;8(2):130.

33. Goad DW, Goad CL, Nagaraja TG. Ruminal microbial and fermentative changes associated with experimentally induced subacute acidosis in steers. J Anim Sci. 1998;76(1):234-41.

34. Deckardt K, Metzler-Zebeli BU, Zebeli Q. Processing barley grain with lactic acid and tannic acid ameliorates rumen microbial fermentation and degradation of dietary fibre in vitro. J Sci Food Agr. 2016;96(1):223-31.

35. Metzler-Zebeli BU, Khol-Parisini A, Gruber L, Zebeli Q. Microbial populations and fermentation profiles in rumen liquid and solids of Holstein cows respond differently to dietary barley processing. J Appl Microbiol. 2015;119(6):1502-14.

36. Jami E, Mizrahi I. Composition and similarity of bovine rumen microbiota across individual animals. PLoS One. 2012;7(3):e33306.
37. Kong Y, Teather R, Forster R. Composition, spatial distribution, and diversity of the bacterial communities in the rumen of cows fed different forages. FEMS Microbiol Ecol. 2010;74(3):612-22.

38. Huws SA, Kim EJ, Cameron SJS, Girdwood SE, Davies L, Tweed J, Vallin H, Scollan ND. Characterization of the rumen lipidome and microbiome of steers fed a diet supplemented with flax and echium oil. Microb Biotechnol. 2015;8(2SI):331-41.

39. Boone DR, Castenholz RW, Garrity GM. Bergey's manual of systematic bacteriology. New York: Springer; 2001.

40. Mrazek J, Tepsic K, Avgustin G, Kopecny J. Diet-dependent shifts in ruminal butyrate-producing bacteria. Folia Microbiol. 2006;51(4):294-8.

41. Pope PB, Smith W, Denman SE, Tringe SG, Barry K, Hugenholtz P, McSweeney CS, McHardy AC, Morrison M. Isolation of Succinivibrionaceae implicated in low methane emissions from Tammar wallabies. Science. 2011:333(6042):646-8

42. McCabe MS, Cormican P, Keogh K, O'Connor A, O'Hara E, Alejandro Palladino R, Kenny DA, Waters SM. Illumina MiSeq phylogenetic amplicon sequencing shows a large reduction of an uncharacterised Succinivibrionaceae and an increase of the Methanobrevibacter gottschalki clade in feed restricted cattle. PLoS One. 2015;10(7):e0133234.

43. Li RW, Wu S, Baldwin RL, Li W, Li C. Perturbation dynamics of the rumen microbiota in response to exogenous butyrate. PLoS One. 2012;7(1):e29392.

44. Wood BJB. The lactic acid Bacteria, The lactic acid bacteria in health and disease, vol. 1; 1992. p. 485

45. Strepis N, Sanchez-Andrea I, van Gelder AH, van Kruistum H, Shapiro N, Kyrpides N, Goeker M, Klenk H, Schaap P, Stams AJM, et al. Description of Trichococcus ilyis sp. nov. by combined physiological and in silico genome hybridization analyses. Int J Syst Evol Micr. 2016;66(10):3957-63.

46. Dai Y, Zhang L, Li Y, Li Y, Deng X, Wang T, Yang F, Tian Y, Li N, Zhou X, et al. Characterization of Trichococcus paludicola sp. nov. and Trichococcus alkaliphilus sp. nov., isolated from a high-elevation wetland, by phenotypic and genomic analyses. Int J Syst Evol Micr. 2018:68(1):99-105.

47. Gao Z, Xu X, Ruan L. Enrichment and characterization of an anaerobic cellulolytic microbial consortium SQD-1.1 from mangrove soil. Appl Microbiol Biot. 2014;98(1):465-74

48. Matsui $\mathrm{H}$, Ogata $\mathrm{K}$, Tajima $\mathrm{K}$, Nakamura M, Nagamine $T$, Aminov Rl, Benno $\mathrm{Y}$. Phenotypic characterization of polysaccharidases produced by four Prevotella type strains. Curr Microbiol. 2000:41(1):45-9.

49. Purushe J, Fouts DE, Morrison M, White BA, Mackie RI, Coutinho PM, Henrissat B, Nelson KE. Comparative genome analysis of Prevotella ruminicola and Prevotella bryantii: insights into their environmental niche. Microb Ecol. 2010;60(4):721-9.

50. Matsui H, Ushida K, Miyazaki K, Kojima Y. Use of ratio of digested xylan to digested cellulose $(X / C)$ as an index of fiber digestion in plant cellwall material by ruminal microorganisms. Anim Feed Sci Tech. 1998; 71(3-4):207-15

51. Attwood GT, Reilly K. Identification of proteolytic rumen bacteria isolated from New-Zealand cattle. J App Bact. 1995;79(1):22-9.

52. Wallace RJ. The proteolytic systems of ruminal microorganisms. Ann Zootech. 1996;45(SUPP1):301-8

53. Chiquette J, Allison MJ, Rasmussen MA. Prevotella bryantii $25 \mathrm{~A}$ used as a probiotic in early-lactation dairy cows: effect on ruminal fermentation characteristics, milk production, and milk composition. J Dairy Sci. 2008; 91(9):3536-43.

54. Garrity GM, Brenner DJ, Krieg NR, Staley JT. Introductory essays. In: Bergey's manual of systematic bacteriology: the Proteobacteria. New York: Springer; 2005.

55. Zhang S, Song W, Yu M, Lin X. Comparative genomics analysis of five Psychrobacter strains isolated from world-wide habitats reveal high intragenus variations. Extremophiles. 2017;21(3):581-9.

56. Amato $P$, Christner BC. Energy metabolism response to low-temperature and frozen conditions in Psychrobacter cryohalolentis. Appl Environ Microb. 2009:75(3):711-8.

57. Ayala-del-Rio HL, Chain PS, Grzymski JJ, Ponder MA, Ivanova N, Bergholz PW, Di Bartolo G, Hauser L, Land M, Bakermans C, et al. The genome sequence of Psychrobacter arcticus 273-4, a psychroactive siberian permafrost bacterium, reveals mechanisms for adaptation to low temperature growth. Appl Environ Microb. 2010;76(7):2304-12.

58. Lin X, Cui S, Xu G, Wang S, Ning D, Shen J. Cloning and heterologous expression of two cold-active lipases from the Antarctic bacterium Psychrobacter sp. G. Polar Res. 2010;29(3):421-9. 
59. Ringo E, Sperstad S, Myklebust R, Mayhew TM, Olsen RE. The effect of dietary inulin on aerobic bacteria associated with hindgut of Arctic charr (Salvelinus alpinus L.). Aquac Res. 2006;37(9):891-7.

60. Sun Y, Yang H, Ma R, Zhang C, Lin W. Effect of dietary administration of Psychrobacter sp. on the growth, feed utilization, digestive enzymes and immune responses of grouper Epinephelus coioides. Aquac Nutr. 2011;17(3): E733-40.

61. Ventura M, Canchaya C, Tauch A, Chandra G, Fitzgerald GF, Chater KF, van Sinderen D. Genomics of Actinobacteria: tracing the evolutionary history of an ancient phylura. Microbiol Mol Biol R. 2007;71(3):495.

62. Duranti S, Milani C, Lugli GA, Mancabelli L, Turroni F, Ferrario C, Mangifesta M, Viappiani A, Sanchez B, Margolles A, et al. Evaluation of genetic diversity among strains of the human gut commensal Bifidobacterium adolescentis. Sci Rep. 2016;6:23971.

63. Duranti S, Turroni F, Lugli GA, Milani C, Viappiani A, Mangifesta M, Gioiosa L, Palanza P, van Sinderen D, Ventura M. Genomic characterization and transcriptional studies of the starch-utilizing strain Bifidobacterium adolescentis 22L. Appl Environ Microb. 2014;80(19):6080-90.

64. Seo JK, Kim S, Kim MH, Upadhaya SD, Kam DK, Ha JK. Direct-fed microbials for ruminant animals. Asian Austral J Anim. 2010;23(12):1657-67.

65. Dicks LMT, Botes M. Probiotic lactic acid bacteria in the gastro-intestinal tract: health benefits, safety and mode of action. Benef Microbes. 2010;1(1):11-29.

66. Fernandez-Navarro T, Salazar N, Gutierrez-Diaz I, Sanchez B, Ruas-Madiedo P, de Los Reyes-Gavilan CG, Margolles A, Gueimonde M, Gonzalez S. Bioactive compounds from regular diet and faecal microbial metabolites. Eur I Nutr. 2018;57(2):487-97.

67. Rios-Covian D, Gueimonde M, Duncan SH, Flint HJ, de Los Reyes-Gavilan CG. Enhanced butyrate formation by cross-feeding between Faecalibacterium prausnitzii and Bifidobacterium adolescentis. FEMS Microbiol Lett. 2015;362(21):fnv176.

68. Flint HJ, Bayer EA, Rincon MT, Lamed R, White BA. Polysaccharide utilization by gut bacteria: potential for new insights from genomic analysis. Nat Rev Microbiol. 2008:6(2):121-31.

69. Duncan SH, Louis P, Flint HJ. Lactate-utilizing bacteria, isolated from human feces, that produce butyrate as a major fermentation product. Appl Environ Microb. 2004;70(10):5810-7.

Ready to submit your research? Choose BMC and benefit from:

- fast, convenient online submission

- thorough peer review by experienced researchers in your field

- rapid publication on acceptance

- support for research data, including large and complex data types

- gold Open Access which fosters wider collaboration and increased citations

- maximum visibility for your research: over $100 \mathrm{M}$ website views per year

At BMC, research is always in progress.

Learn more biomedcentral.com/submissions 